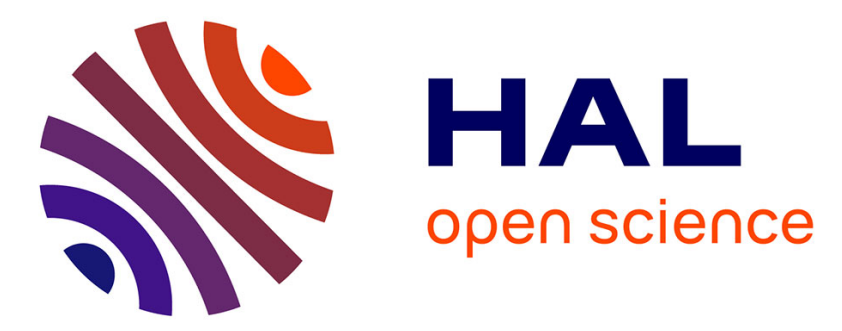

\title{
Influence of the lubricating oil pressure and temperature on the performance at low speeds of a centrifugal compressor for an automotive engine Pierre Podevin, Adrian Clenci, Georges Descombes
}

\section{- To cite this version:}

Pierre Podevin, Adrian Clenci, Georges Descombes. Influence of the lubricating oil pressure and temperature on the performance at low speeds of a centrifugal compressor for an automotive engine. Applied Thermal Engineering, 2010, 31 (2-3), pp.194. 10.1016/j.applthermaleng.2010.08.033 . hal00692332

\section{HAL Id: hal-00692332 \\ https://hal.science/hal-00692332}

Submitted on 30 Apr 2012

HAL is a multi-disciplinary open access archive for the deposit and dissemination of scientific research documents, whether they are published or not. The documents may come from teaching and research institutions in France or abroad, or from public or private research centers.
L'archive ouverte pluridisciplinaire HAL, est destinée au dépôt et à la diffusion de documents scientifiques de niveau recherche, publiés ou non, émanant des établissements d'enseignement et de recherche français ou étrangers, des laboratoires publics ou privés. 


\section{Accepted Manuscript}

Title: Influence of the lubricating oil pressure and temperature on the performance at low speeds of a centrifugal compressor for an automotive engine

Authors: Pierre Podevin, Adrian Clenci, Georges Descombes

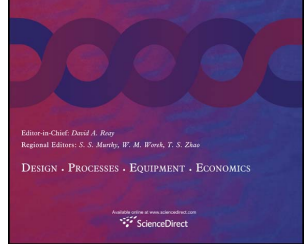

PII:

S1359-4311(10)00376-5

DOI:

10.1016/j.applthermaleng.2010.08.033

Reference: $\quad$ ATE 3226

To appear in: Applied Thermal Engineering

Received Date: 26 October 2009

Revised Date: 14 August 2010

Accepted Date: 31 August 2010

Please cite this article as: P. Podevin, A. Clenci, G. Descombes. Influence of the lubricating oil pressure and temperature on the performance at low speeds of a centrifugal compressor for an automotive engine, Applied Thermal Engineering (2010), doi: 10.1016/j.applthermaleng.2010.08.033

This is a PDF file of an unedited manuscript that has been accepted for publication. As a service to our customers we are providing this early version of the manuscript. The manuscript will undergo copyediting, typesetting, and review of the resulting proof before it is published in its final form. Please note that during the production process errors may be discovered which could affect the content, and all legal disclaimers that apply to the journal pertain. 


\title{
Influence of the lubricating oil pressure and temperature
}

\section{on the performance at low speeds of a centrifugal compressor for an}

\section{automotive engine}

\section{${ }^{1}$ Pierre PODEVIN*, ${ }^{1,2}$ Adrian CLENCI, ${ }^{1}$ Georges DESCOMBES}

\author{
${ }^{1}$ Conservatoire national des arts et métiers (Cnam)
}

Laboratoire de génie des procédés pour l'environnement, l'énergie et la santé (LGP2ES EA21)

Case 333, 292 rue Saint-Martin 75141 Paris cedex 03 France

Phone : +331402724 42, Fax : +33142719329

${ }^{2}$ University of Pitesti, Automotive Department, Romania

1, Tg. Din Vale street, Piteşti - 110040, Argeş, Romania

E-mail : pierre.podevin@cnam.fr

*Corresponding author

\begin{abstract}
:
Currently, turbocharged common rail high pressure direct injection Diesel engines are regarded as state-of-the-art. The use of the turbocharging technique in gasoline engines is also increasing, in order to achieve further fuel consumption reductions via downsizing. As the specific power outputs of both Diesel and gasoline engines rise, the low-end torque behavior of such engines and turbo-lag are becoming increasingly critical. This is primarily a result of the specific characteristics of turbochargers and internal combustion engines themselves.

When it comes to matching a turbocharger to a given engine, the compressor map over the entire operating area has to be known with sufficient accuracy, especially at low turbocharger speeds
\end{abstract}


corresponding to the engine low part loads (i.e. urban traffic). This map is established assuming the adiabatic behavior of the compressor. While this assumption is acceptable at rather high speeds, it is no longer valid for low speeds, and for that reason, the compressor map in this area is not provided by the turbocharger manufacturer.

Worldwide, there are no standard guidelines for the correct measurement and calculation of turbocharger maps at low speeds. In collaboration with a French automotive manufacturer, a special method was therefore designed and applied within the laboratory LGP2ES at Cnam Paris in order to obtain the compressor low speed map. A special torquemeter was fitted in a cold turbocharger test bench, affording measurements from 30,000 rpm to $120,000 \mathrm{rpm}$. The experimental results presented in this paper show the combined effect of the lubricating oil temperature and pressure on the compressor performance, expressed in terms of compression ratio, compressor power, isentropic efficiency and mechanical efficiency. These results afford a better estimation of the compressor map at low speeds.

\section{Keywords:}

Compressor, torquemeter, isentropic efficiency, mechanical efficiency, friction losses 


\section{Nomenclature}

$\mathrm{c}_{\mathrm{p}}=$ specific heat;

$\mathrm{k}=$ specific heat ratio;

$\mathrm{N}=$ turbocharger rotational speed ;

$\mathrm{P}=$ compressor power;

$\mathrm{p}_{\mathrm{i} 1}=$ compressor inlet total pressure;

$\mathrm{p}_{\mathrm{i} 2}=$ compressor outlet total pressure;

$\mathrm{P}_{\mathrm{f}}=$ friction power loss ;

$\mathrm{P}_{\mathrm{m}}=$ mechanical power at the turbocharger shaft (measured with the torquemeter);

$\mathrm{q}_{\mathrm{m}}=$ mass air flow rate;

$\mathrm{T}_{\mathrm{i} 1}=$ compressor inlet total temperature;

$\mathrm{T}_{\mathrm{i} 2}=$ compressor outlet total temperature after real compression;

$\mathrm{T}_{\mathrm{i} 2}$, = compressor outlet total temperature after isentropic compression;

$\mathrm{T}_{\mathrm{oil}}=$ lubricating oil temperature;

$\mathrm{W}_{\text {is }}=$ isentropic work used for the isentropic compression of air ;

$\mathrm{W}_{\text {real }}=$ real work used for the real compression of air;

$\Delta \mathrm{T}_{\mathrm{is}}=$ isentropic temperature variation between compressor inlet and outlet;

$\Delta \mathrm{T}_{\text {real }}=$ real temperature variation between compressor inlet and outlet;

$\eta_{\text {is }}=$ compressor isentropic efficiency;

$\eta_{\mathrm{m}}=$ turbocharger mechanical efficiency;

$\tau_{\mathrm{c}}=$ compressor compression ratio; 


\section{INTRODUCTION}

Downsizing automotive engines is currently considered as one of the most promising ways to improve fuel economy with an acceptable cost-to-benefit ratio. The challenge is to reduce the engine displacement while keeping the same performance in terms of torque and power as the initial larger engine and to simultaneously ensure an improvement in engine efficiency. This cannot be done without increasing the density of the air introduced into the engine. Turbocharging is the boosting technology generally used in today's market and is the subject of extensive research, which seeks to overcome its drawbacks, such as low-end torque, turbo-lag [1,2] and compressor surge $[3,4]$.

When it comes to matching a turbocharger to a given engine, one problem is the operation of these two machines which have highly different characteristics. The turbocharger is a continuous flow machine whereas the reciprocating engine is a discontinuous flow machine, which generally operates over a wide range of speed and torque $[5,6]$.

Consequently, improving the operation of highly downsized, turbocharged engines requires knowledge of the turbine and compressor maps over the entire operating area. At low part loads corresponding to urban traffic according to the NEDC (New European Driving Cycle) test, the turbocharger speed is less than $100,000 \mathrm{rpm}[9,16]$. Unfortunately in this area, the compressor map is not provided by the turbocharger manufacturer. If the maximum turbocharger speed is 150,000 $\mathrm{rpm}$, characteristic curves are not given for speeds less than $70,000 \mathrm{rpm}$, or $90,000 \mathrm{rpm}$ if the maximum speed is $240,000 \mathrm{rpm}$. The reason is that these maps are based on the assumption of adiabatic behavior of the compressor, an assumption that is no longer valid at low turbocharger speeds [7].

The isentropic efficiency of the compressor is deduced from measurements of compressor inlet and outlet parameters such as pressure and temperature. At low speeds, the inlet-outlet variation in temperature is small, so the inherent measurement errors become important and adversely influence the accuracy of the calculation of compressor power and isentropic efficiency. Moreover, in this 
case, thermal transfer cannot be neglected and standard calculations can no longer be used, [7, 8], especially on hot gas stands which are widely used by turbocharger manufacturers.

Concerning turbine performances, on a hot gas stand, the turbine obviously cannot be considered adiabatic and a common practice is to give the efficiency as the product of mechanical efficiency and isentropic efficiency of the compressor, which implies doing the usual measurements on the compressor during turbine tests.

Worldwide, there are no standard guidelines for the correct measurement and calculation of turbocharger maps at low speeds.

To achieve a better understanding of turbocharger performances, tests can be done on a cold test rig. This enables the isentropic efficiency of the turbine to be determined. In the present study, this is the approach adopted. Similar experiments have been conducted at low speed [8], using a watercooled turbo to minimize heat exchange.

Another way to improve our knowledge of turbocharger efficiency is to assess mechanical power losses. In our case, this has been accomplished thanks to a torquemeter: if power losses are known, we are able to calculate the power given to the air flow in spite of heat exchange. Work is also in progress on bearing losses, using a combined experimental and numerical approach [9].

Experiments on measurements of bearing losses have been done by Honeywell Turbocharger Technologies [10]. The turbine was carefully insulated (adiabatic conditions) and experiments were performed at $100^{\circ} \mathrm{C}$. The compressor blades were removed, so compressor power could be neglected. The laboratory at Stuttgart University [11] has designed a specific test bench for the direct study of bearing losses. Turbocharger wheels were removed and axial forces were generated by an electromagnetic device. Torque was measured with a high degree of precision for a rotary strain gauge torque sensor. Results are expressed in terms of percentage of power and torque; while this does not provide access to the real value, the results of power or torque evolution are in agreement with our experiments. 
An interesting method based on turbocharger inertia and measurements of speed deceleration has been proposed by the University of Hanover [12]. Unfortunately, it seems that the friction power determined by this method is overestimated.

The calculations presented in the above-mentioned papers highlight the difficulties of approximating bearing losses on the basis of empirical calculations.

In collaboration with a French automotive manufacturer, a special method was therefore designed and applied within the laboratory LGP2ES at Cnam Paris in order to obtain the compressor low speed map. A special torquemeter was fitted on a standard turbocharger test bench, affording measurements from $30,000 \mathrm{rpm}$ to $120,000 \mathrm{rpm}[7,14]$.

\section{TURBOCHARGER TEST RIG SETUP}

Turbocharger maps are usually acquired on hot test benches [13], or cold test benches [7, 8]. In the former case, the heat flux between the hot turbine and the cold compressor causes overestimation of the calculated compressor power and underestimation of isentropic efficiency. This error, due to the assumption of adiabatic behavior of the compressor, becomes even greater at low turbocharger speeds, as stated before $[7,8,13]$.

As there is no standard that provides detailed descriptions of the correct measurement and calculation method to obtain turbocharger maps, experiments were conducted in the LGP2ES laboratory at Cnam Paris on a standard cold turbocharger test rig fitted with a torquemeter specially designed for such applications. Torque was measured from shaft twist, which was deduced from the phase difference between two toothed wheels located at either end of the shaft [14]. The same device gives the rotational speed and hence the power. The main characteristics of the torquemeter are as follows:

- Maximum speed: 120,000 rpm

- Shaft diameter: $2.46 \mathrm{~mm}$ 
- Maximum power: $5 \mathrm{~kW}$

- Accuracy: \pm 0.0016 N.m

- Grease lubricating ceramic ball bearings

The test rig layout is shown on figure 1 and a picture of the torquemeter and the turbocharger on figure 2 .

Fig.1. Schematic of test rig

Fig. 2. Test bench

The turbine is fed by dry compressed air under steady flow and in this application is used only for driving the compressor. The air source is a $700 \mathrm{~m}^{3}$ tank under 25 bar. The turbine flow rate is controlled by a valve and a second valve is used to modify the operating conditions of the compressor. The compressor map can thus be found by adjusting these valves. Both center housings are fed by the lubricating unit with SAE $15-30 \mathrm{~W}$ oil. Oil inlet temperature and pressure are adjustable, respectively from 20 to $120^{\circ} \mathrm{C}$ and from 0.5 to 4 bar.

\section{DETERMINATION OF COMPRESSOR PERFORMANCE}

As mentioned above, usually the compressor is presumed to have an adiabatic behavior, which means its isentropic efficiency is calculated as follows:

$\eta_{\text {is }}=\frac{W_{i s}}{W_{\text {real }}}=\frac{\Delta T_{i s}}{\Delta T_{\text {real }}}=\frac{T_{i 2^{\prime}}-T_{i 1}}{T_{i 2}-T_{i 1}}=\frac{T_{i 1} \cdot\left(\tau_{c}^{\frac{k-1}{k}}-1\right)}{T_{i 2}-T_{i 1}}$,

where

$W_{i s}$ and $W_{\text {real }}$ are the isentropic and real compression work,

$\Delta \mathrm{T}_{\text {is }}, \Delta \mathrm{T}_{\text {real }}$ are respectively the isentropic and real temperature variation between compressor inlet and outlet (Figure 3) and $\mathrm{k}$ is the specific heat ratio,

$T_{i 1}, T_{i 2}$ are the compressor inlet and outlet total temperatures, 
and $p_{i 1}$ and $p_{i 2}$ are the compressor inlet and outlet total pressures.

Fig. 3. Entropic diagram for the compressor

Furthermore, based on measurements, the following can also be calculated:

- compression ratio:

$$
\tau_{c}=\frac{p_{i 2}}{p_{i 1}},
$$

- compressor power, i.e. the power received by the air flow rate:

$$
P=q_{m} \cdot c_{p}\left(T_{i 2}-T_{i 1}\right),
$$

where $q_{m}$ is the air mass flow rate, and $c_{p}$ is the air specific heat at constant pressure.

The pressure is evaluated by different strain gauge transducers adapted to the measurement scale, while the temperature is measured by platinum resistance thermometers. The mass air flow rate is determined by a sharp edge orifice.

All sensor signals are converted to $0-5$ voltage and sent to a data acquisition card. For each signal, 100 data acquisitions are done at $10 \mathrm{~Hz}$, and the mean values recorded.

Thanks to the special torquemeter fitted between the turbine and compressor, the turbocharger's mechanical efficiency is found with the following relation:

$\eta_{m}=\frac{\boldsymbol{P}}{\boldsymbol{P}_{m}}=\frac{\boldsymbol{P}_{m}-\boldsymbol{P}_{f}}{\boldsymbol{P}_{m}}=1-\frac{\boldsymbol{P}_{f}}{\boldsymbol{P}_{m}}$

where $\mathrm{P}_{\mathrm{m}}$ is the mechanical power given to the compressor shaft by the turbine, which is provided by the torquemeter, and $\mathrm{P}_{\mathrm{f}}$ is the power loss to overcome friction within the turbocharger shaft bearings.

The friction losses can thus be estimated, provided that correct values for the compressor power are available. This is the case if heat exchange is minimized. In general, particularly at low turbocharger speeds, the compressor outlet total temperature is affected by the temperature 
conditions of the lubricating oil, air flow inside the compressor and ambient temperature. In the situation presented in this paper (cold test bench), minimizing heat exchange simply means handling the lubricating oil temperature parameters, as explained hereafter.

This experimental study was conducted as a parametric study, in order to assess the combined effect of lubricating oil temperature and pressure on the compressor performance. It was expected that the results thus obtained would advance our knowledge of the compressor map in the low speed range. More than 60 experiments were therefore performed but only the most relevant results are presented hereafter.

\section{EXPERIMENTAL RESULTS}

\subsection{Influence of lubricating oil temperature on the compressor performance}

As already discussed, the lubricating oil temperature appears to have a strong impact on the turbocharger performance. Mechanical power losses depend on oil viscosity, which is directly linked to oil temperature. Furthermore, heat exchange increases for high oil temperature and low rotational speeds.

Experiments show little difference in mechanical power given to the compressor shaft by the turbine, except for low rotational speeds (Figure 4, $a$ ). In figure $4, b$, it can be clearly seen that when the oil temperature is increased, the mechanical power provided by the torquemeter drops, with a difference of about $40 \%$ between the two extreme situations $\left(20{ }^{\circ} \mathrm{C}\right.$ and $\left.80{ }^{\circ} \mathrm{C}\right)$. Although this difference between the two situations persists, when the speed increases the difference narrows and at $110,000 \mathrm{rpm}$ it can be neglected.

Fig.4. Mechanical power vs. air flow rate 
For a given rotational speed and constant lubricating oil pressure, the oil temperature, as expected, had a negligible influence on the pressure ratio (Figure 5). However, it influences isentropic efficiency, especially at low rotational speeds (Figure 6). This is due to the non-adiabaticity of the compressor, as explained below.

Fig.5. Compression ratio vs. air flow rate Fig.6. Isentropic efficiency vs. air flow rate

\subsection{Influence of lubricating oil pressure on the compressor performances}

Generally, turbochargers are tested with a constant feeding oil pressure. However, during experimentation, an effect of oil pressure was clearly noticed. When the inlet oil pressure was changed, a variation in the turbocharger speed was observed, although the valves controlling the air flow rate of the compressor and the turbine were maintained in a fixed position. For instance, when the oil inlet pressure was decreased from 4 to 1 bar (points 1 to 7 in figure 7 ) and then increased back to 4 bar (points 7 to 10 in figure 7), a change in turbocharger speed from 55,000 to 32,000 rpm was observed, albeit with some discontinuities and hysteresis. This change of speed has an effect on the pressure ratio and air flow rate, as indicated on figure 8 .

Fig. 7. Rotational speed vs. oil pressure

Fig. 8. Compression ratio vs. air flow rate

Experiments at a given rotational speed and constant lubricating oil inlet temperature showed that the oil pressure has no influence on the pressure ratio and isentropic efficiency, which seems logical (figures 9 and 10).

Fig. 9 Compression ratio vs. air flow rate Fig. 10 Isentropic efficiency vs. air flow rate

The effect of oil pressure on mechanical power appears to be small (figure 11).

Fig. 11 Mechanical power vs. air flow rate 
The variation in mechanical power, for an oil pressure change from 2 to 4 bar, is approximately $5 \%$ at 70,000 rpm and $3 \%$ at $110,000 \mathrm{rpm}$. Nevertheless it must not be neglected at low speed. A difference of $24 \%$ is obtained at 30,000 rpm, which could explain the speed variation on figure 7 , also noticed on other turbochargers.

The effect of oil pressure on mechanical power is quite unexpected, as for a given rotational speed, mechanical power losses depend primarily on oil viscosity, which is linked to temperature only and not to pressure. However, an explanation for this phenomenon was put forward in a recent numerical study [9]: while the oil pressure has no effect on viscosity, it does have an effect on oil flow. When the pressure increases, the oil flow also increases, leading to a better cooling of the journal bearings. Oil temperature within the inner clearance of journal bearings thereby decreases, viscosity increases and mechanical power losses also increase, entailing an increase in mechanical power.

\section{ANALYSIS OF THE RESULTS}

\subsection{Isentropic efficiency of compressor}

Usually, on our test bench, turbocharger characteristic curves are established with a lubricating oil pressure of 3 bar and an oil tank temperature of about $60^{\circ} \mathrm{C}$.

At low rotational speeds, oil pressure and temperature at the inlet of the compressor have to be set precisely. The effect of oil inlet temperature for experiments done at 30,000 rpm is clearly observed.

When the inlet lubricating oil temperature is set at $20^{\circ} \mathrm{C}$, the outlet oil temperature is about $32^{\circ} \mathrm{C}$. This increase of $12^{\circ} \mathrm{C}$ is due to mechanical power losses converted to heat and physically, this result is logical. When the oil temperature is set at $80^{\circ} \mathrm{C}$, the oil temperature difference between outlet and inlet is about $-7^{\circ} \mathrm{C}$. This means either that energy is given to the shaft by the lubricating oil or that the oil is cooled by heat exchange due to air flow in the compressor. The latter hypothesis is 
physically the only realistic one and shows that in these conditions, heat exchange between lubricating oil and turbocharger is high.

As outlined before, this heat exchange undoubtedly has a direct effect on the calculated isentropic efficiency. For a pressure ratio of 1.02, the increase in isentropic temperature between compressor outlet and inlet is only $1.7^{\circ} \mathrm{C}$. This means that if heat exchanges are minimized (i.e. if approaching adiabatic behavior), the real increase in temperature is $3.2^{\circ} \mathrm{C}$ for an isentropic efficiency of 0.52 . If the real temperature increase is $7.5^{\circ} \mathrm{C}$ (when air flow receives heat from a high lubricating oil temperature), the isentropic efficiency drops to 0.22 .

These simple calculations explain the marked discrepancy in isentropic efficiency curves at 30,000 rpm that can be observed on figure 6 , and emphasize the difficulties encountered when trying to draw the characteristics of compressors at low rotational speeds even with a cold test rig. Often, compressor characteristics curves are established on a test rig where the turbine is fed with hot gases. Consequently, heat exchange is greater and leads to greater inaccuracies, thus to inconsistent isentropic efficiency values.

Nevertheless, the isentropic efficiency can be estimated when heat exchange is minimized. This can be reasonably considered to be the case when the lubricating oil mean temperature through the center housings is almost equal to the compressor air flow temperature. The experiments fulfilling this criterion were therefore selected. Based on this selection, figure 12 presents a better estimation of the compressor map at low speeds.

Fig. 12. Compressor map

\subsection{Mechanical efficiency}

As before, if only the experiments performed in quasi-adiabatic conditions are considered, then relation (3) can be considered as trustworthy and used to calculate the power P given to the air flow (figure 13). As relation (4) shows, the difference between the mechanical power, $\mathrm{P}_{\mathrm{m}}$, given to the 
compressor shaft by the turbine (measured via the torquemeter) and the power $\mathrm{P}$ is the power loss to overcome friction $\left(\mathrm{P}_{\mathrm{f}}\right)$. Put more simply, the power $\mathrm{P}_{\mathrm{f}}$ can be considered constant for a given rotational speed. Mean values of power losses versus turbocharger rotational speeds are drawn in figure 14 .

Fig.13 - Compressor power vs. air flow rate

Fig.14 - Mechanical power losses vs. rotational speed

Using the curves of power given to the air flow in quasi-adiabatic conditions and curves of power losses, the mechanical efficiency can be expressed as a function of air flow (Figure 15).

Fig.15 - Mechanical efficiency vs. air flow rate

This approach has emphasized the great variation in mechanical efficiency for turbocharger speeds lower than $110,000 \mathrm{rpm}$. When the balance of power given by the turbine and power received by the compressor is calculated, a mechanical efficiency of 0.8 to 0.9 is often assumed. As seen in figure 15 , this is not the case for low rotational speeds.

\section{Conclusions}

The objective of this research was to evaluate the influence of lubricating oil temperature and pressure on compressor performance at low speed. In spite of the use of a specific test bench, the study has demonstrated the difficulty of assessing compressor performance at low speed.

First of all, it is important to stress the influence of the heat given by the lubricating oil, which in the case of low speeds leads to serious errors when trying to estimate the compressor isentropic efficiency. Given that the experiments were conducted on a "cold" test rig, it is certainly unrealistic 
to hope for correct results at low speeds on hot test rigs. Thus, starting from the experimental results, only those tests performed in quasi-adiabatic conditions were selected in order to draw the compressor characteristics.

This more reliable approach has allowed a better estimation of the compressor mechanical efficiency. As seen, this efficiency, which is about 0.85 at high speeds, does not exceed 0.3 at $30,000 \mathrm{rpm}$.

Thanks to our test bench equipped with a torquemeter, the difficulty in measuring the power given to the air flow in real conditions (non adiabatic) can be easily overcome if the mechanical efficiency of the turbocharger is known. Unfortunately, the accuracy of theoretical calculations of mechanical power losses are not satisfactory with basic solving methods $[15,16]$ and need to be improved [9]. The present study forms part of a general research program on automotive turbochargers, financed by the French National Research Agency, involving two French automotive manufacturers, two turbocharger manufacturers and three French universities.

The on-going research concern focuses on calculations with a 2D and 3D CFD software and the concurrent enhancement of the test procedure to improve our test bench results. Experiments have been done with insulation of the compressor and hot air, in order to create "new adiabatic" conditions. Furthermore to validate the computation on bearing losses, journal bearings and thrust bearing, the test bench has been equipped with a special device to control axial forces.

\section{Acknowledgments}

The authors would like to express their gratitude to the French institution ADEME (Agence de l'Environnement et de la Maîtrise de l'Energie), Professor Michel Feidt of University Nancy 1, France, for supporting our collaboration and PSA Peugeot Citroën, for providing the torquemeter for this study.

\section{References}


[1] Pagot, A., Duparchy, A., Gautrot, X., Leduc, P., Monnier G. - Combustion Approach for Downsizing: the IFP Concept, Oil\&Gas Science and Technology, Vol. 61 (2006), No. 1, pp. 139 153.

[2] Frei, S., Guzzella, L., Onder C., Nizzola C. - Improved dynamic performance of turbocharged SI engine powertrains using clutch actuation, Control Engineering Practice 14 (2006), pp. 363-373

[3] Galindo, J., Serrano, J.R., Climent, H., Tiseira, A. - Experiments and modelling of surge in small centrifugal compressor for automotive engines, Experimental Thermal and Fluid Science 32 (2008), pp. $818-826$

[4] Toussaint, M., Boudfar, M., Descombes, G., Guilain, S., Lahjaily, Ammar, A., Experimental Study of the Compressor Surge of a Diesel High Performance Engine. Conference on Thermo and Fluid Dynamic processes, THIESEL 2008, September 2008, Valencia, Spain.

[5] Descombes, G., Maroteaux, F., Feidt, M., 2003, Study of the interaction between mechanical energy and heat exchanges applied to IC engines, Applied Thermal Engineering, Vol. 23, issue 16, pp. 2061-2078, Nov. 2003.

[6] Descombes, G., Boudigues, S., 2009, Modelling of waste heat recovery for combined heat and power applications. Applied Thermal Engineering 29 (2009) 2610-2616.

[7] Podevin, P., Toussaint, M., Richard, G., Farinole, G., 2002, Performances of turbocharger at low speed, SYMKOM'02, Compressor \& Turbine Stage Flow Path Theory, Experiment \& User Verification, Lodz, Poland, October 2002.

[8] Otobe, T., Grigoriadis, P., Sens, M., Berndt, R. - Method of performance measurement for low turbocharger speeds, Turbochargers and Turbocharging, Imech, May 19-20, 2010, London, UK.

[9] Deligant, M., Podevin, P., Descombes, G., Vidal, F., Lefebvre, A., Lamquin, T., Computational Fluid Dynamics Calculations of Turbocharger's Bearing Losses, paper 2010-01-1537, SAE International Powertrains, Fuels and Lubricants Meeting, May 2010, Rio de Janeiro, Brazil. 
[10] Lamquin, T., Gjika, K., 2009, Power losses identification on turbocharger hydrodynamic bearing systems: test and prediction, Proceedings of ASME Turbo Expo 2009, Paper GT200959599 pp. 153-162, June 8-12, 2009, Orlando, FL USA.

[11] Schmitt, S., Schmid, W., Hertweck, G., Schlegl, M., Staudacher, S., 2007, High-Precision Measurements of Friction Losses in Turbochargers, Auflladetechnische Konferenz 2007, September 2007, Dresden, Germany.

[12] Seume, J., Ziesenis, B., Wolkerstorfer, J., 2007, Untersuchung und empirische Modellbildung des Reibmomentes, Heft R 537, Informationstagung Motoren, Frühjahr 2007, Frankfurt am Main. [13] Schorn, N., Smiljanowski, V., Spader, U., Stalman, R., Kindl, H. - Turbocharger Turbines in Engine Cycle Simulation, Aufladetechnische Konferenz 2008, September 2008, Dresden, Germany. [14] www.torquemeter.com

[15] Frêne, J., 2004, Butées et Paliers Hydrodynamiques, B5 320, Techniques de l'Ingénieur.

[16] Yoboué, K., Deligant, M., Périlhon, C., Podevin, P., Estimation by calculation of mechanical power losses on automotive turbochargers. The 2nd International Congress on Automotive, Safety and Environment, SMAT, 2008, October 2008, Craiova, Romania 


\title{
Influence of the lubricating oil pressure and temperature
}

\section{on the performance at low speeds of a centrifugal compressor for an}

\section{automotive engine}

\section{${ }^{1}$ Pierre PODEVIN*, ${ }^{1,2}$ Adrian CLENCI, ${ }^{1}$ Georges DESCOMBES}

\author{
${ }^{1}$ Conservatoire national des arts et métiers (Cnam)
}

Laboratoire de génie des procédés pour l'environnement, l'énergie et la santé (LGP2ES EA21)

Case 333, 292 rue Saint-Martin 75141 Paris cedex 03 France

Phone : +331402724 42, Fax : +33142719329

${ }^{2}$ University of Pitesti, Automotive Department, Romania

1, Tg. Din Vale street, Piteşti - 110040, Argeş, Romania

E-mail : pierre.podevin@cnam.fr

*Corresponding author 


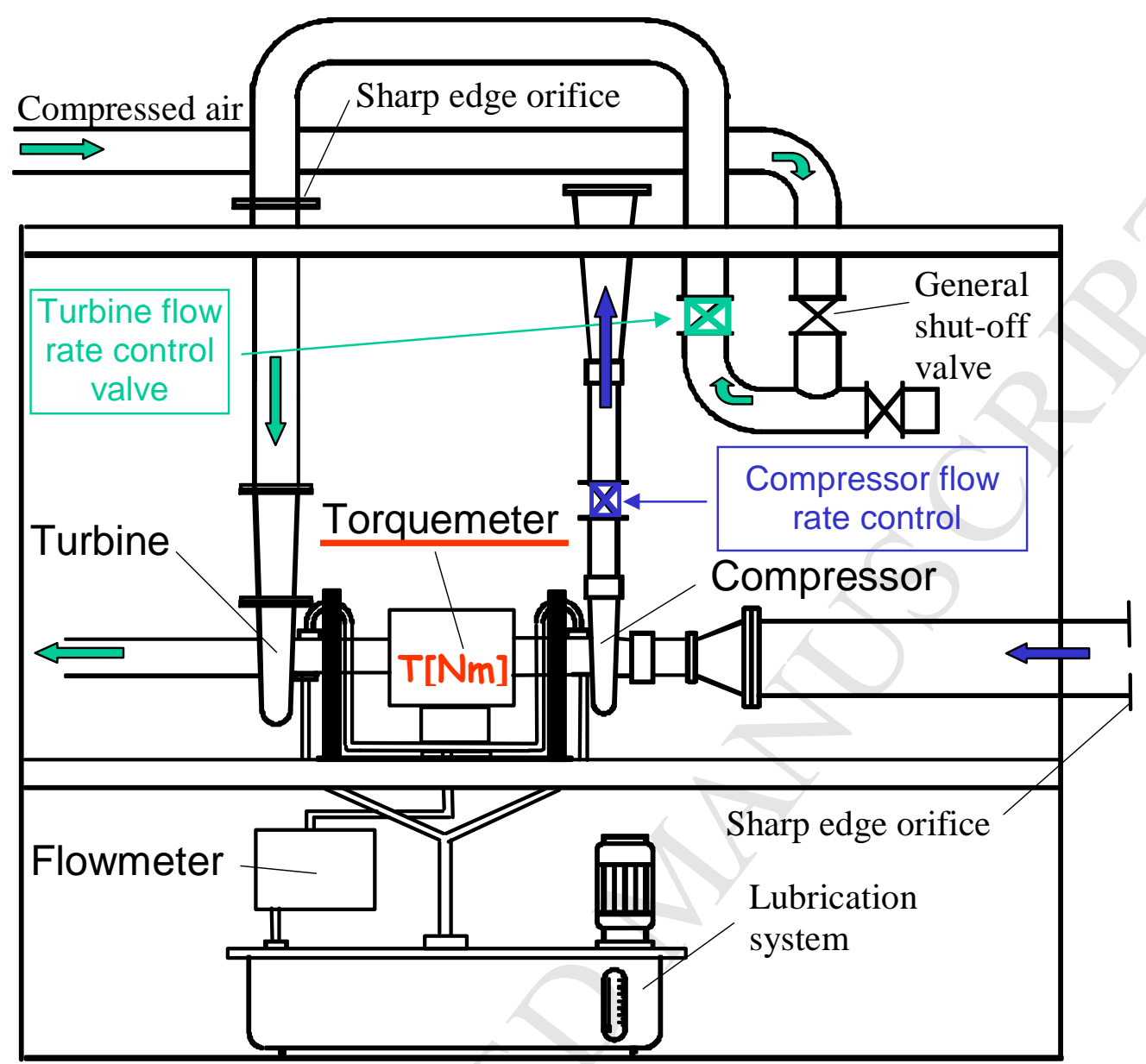

Fig.1 - Schematic of test rig 


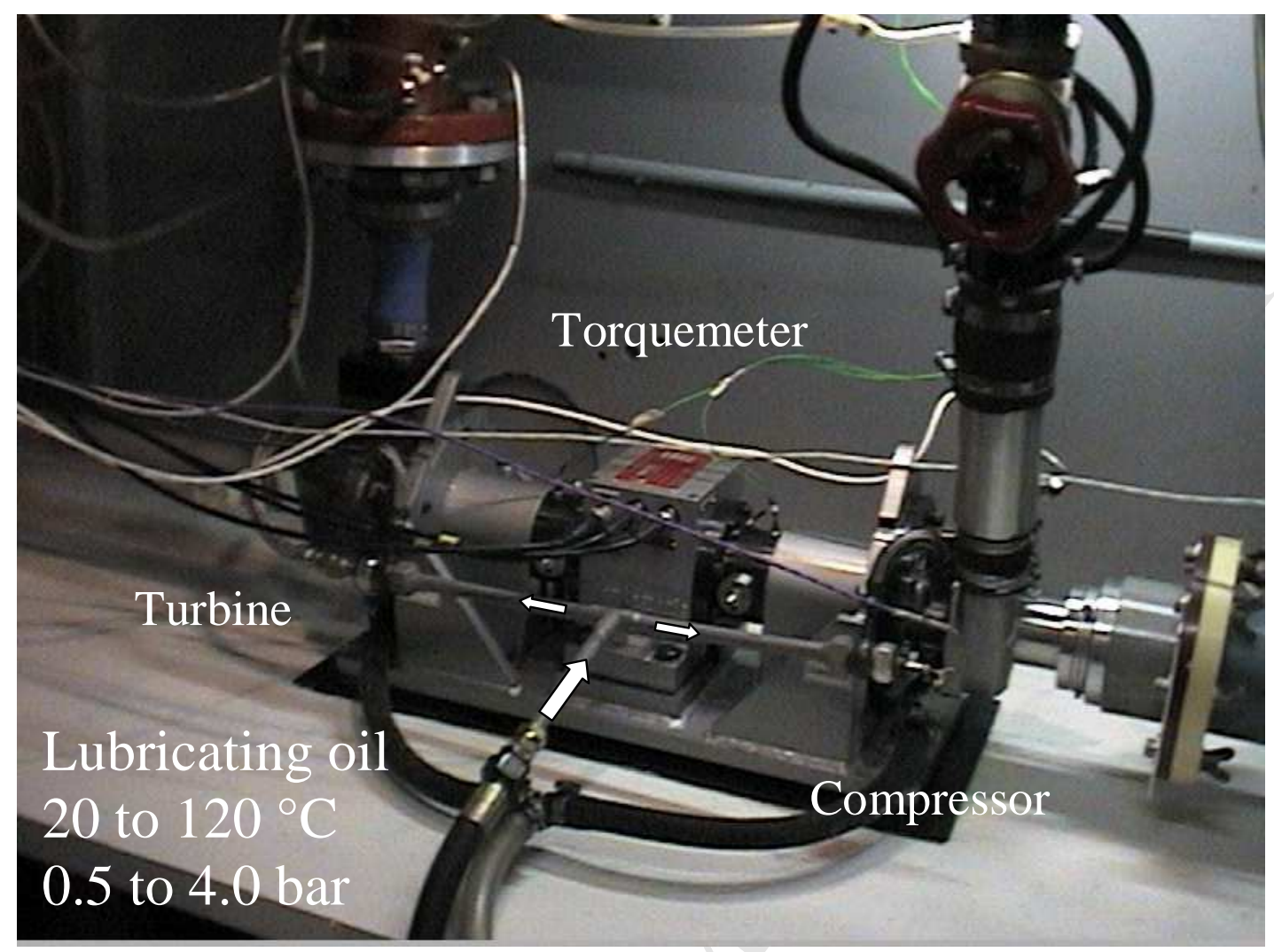

Fig. 2 - Test bench

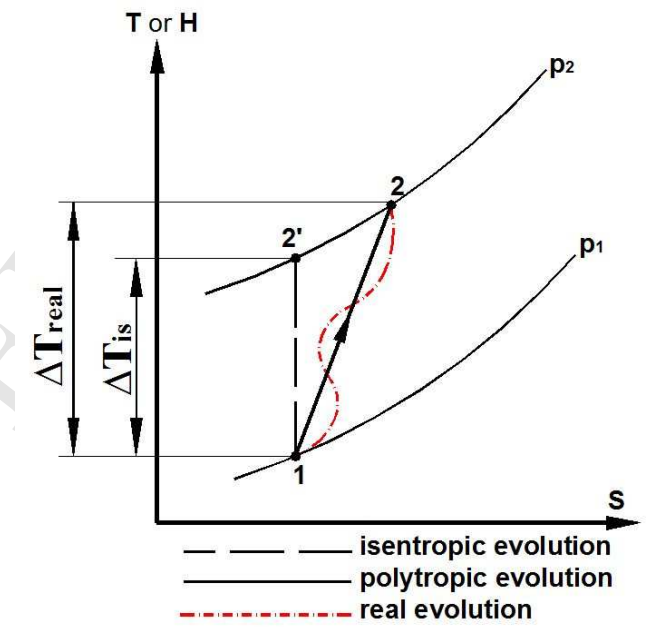

Fig. 3 - Entropic diagram for the compressor 


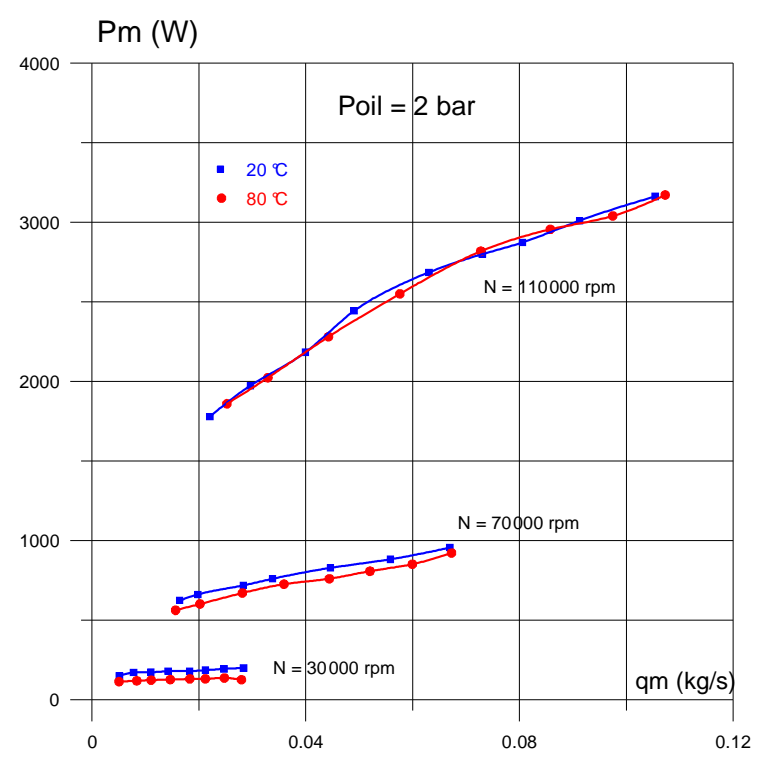

$a$.

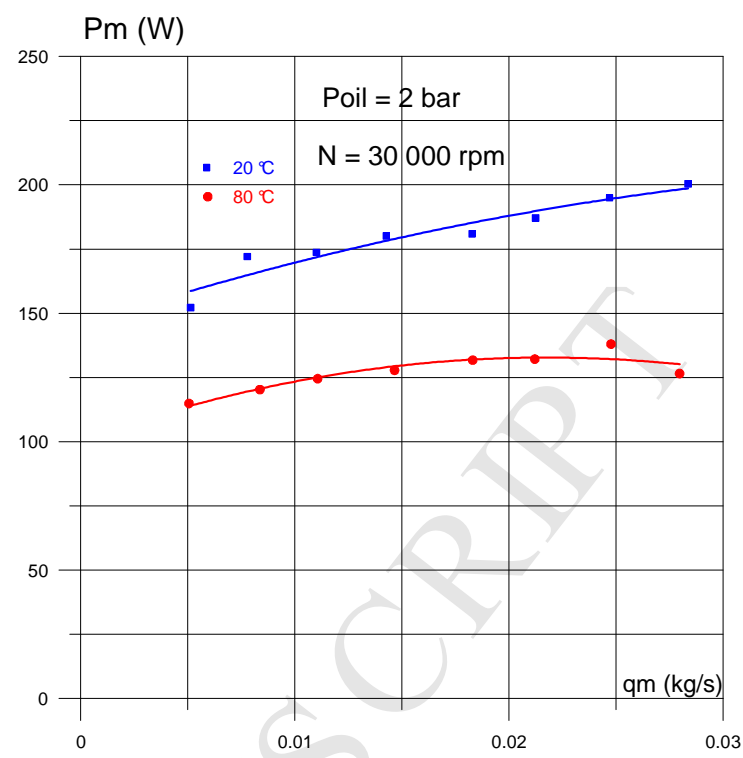

b.

Fig. 4 - Mechanical power vs. air flow rate

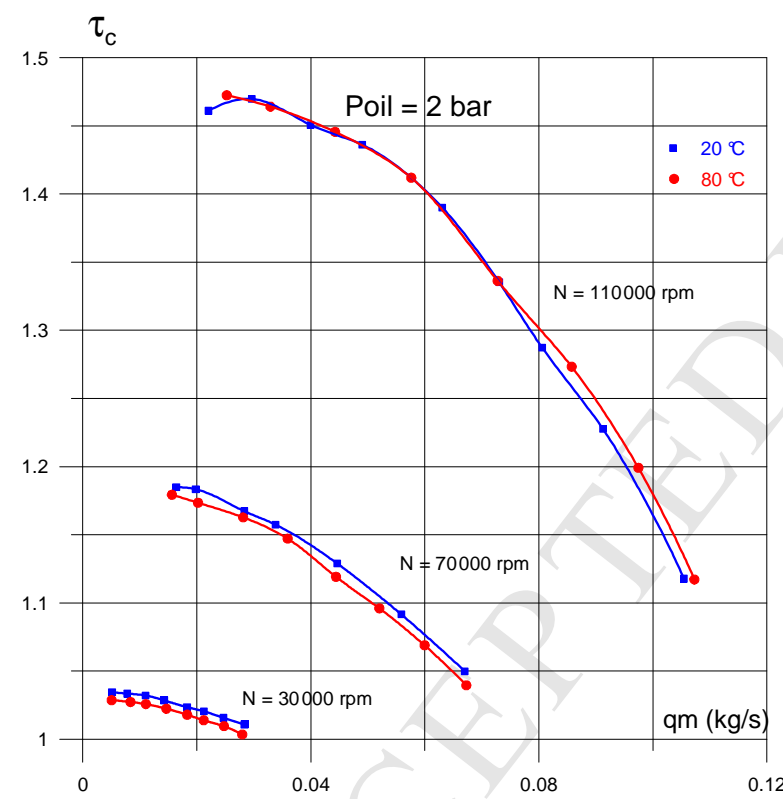

Fig. 5 - Compression ratio vs. air flow rate

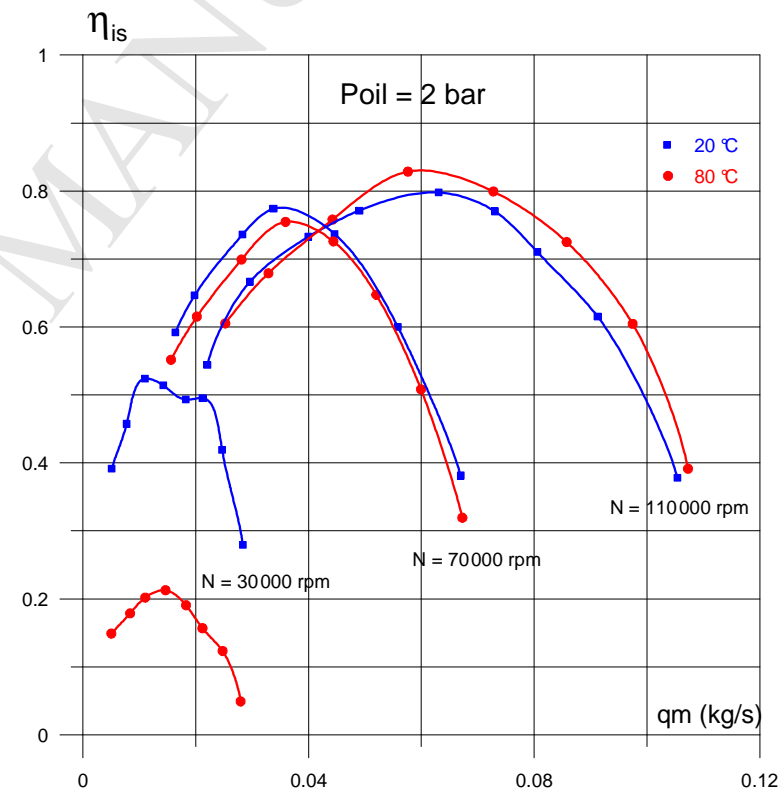

Fig. 6 - Isentropic efficiency vs. air flow rate 


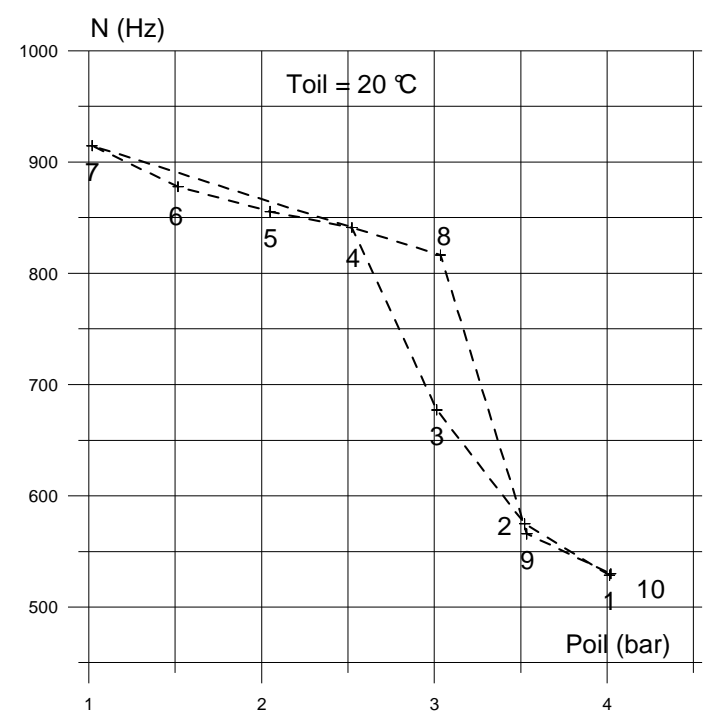

Fig. 7 - Rotational speed vs. oil pressure

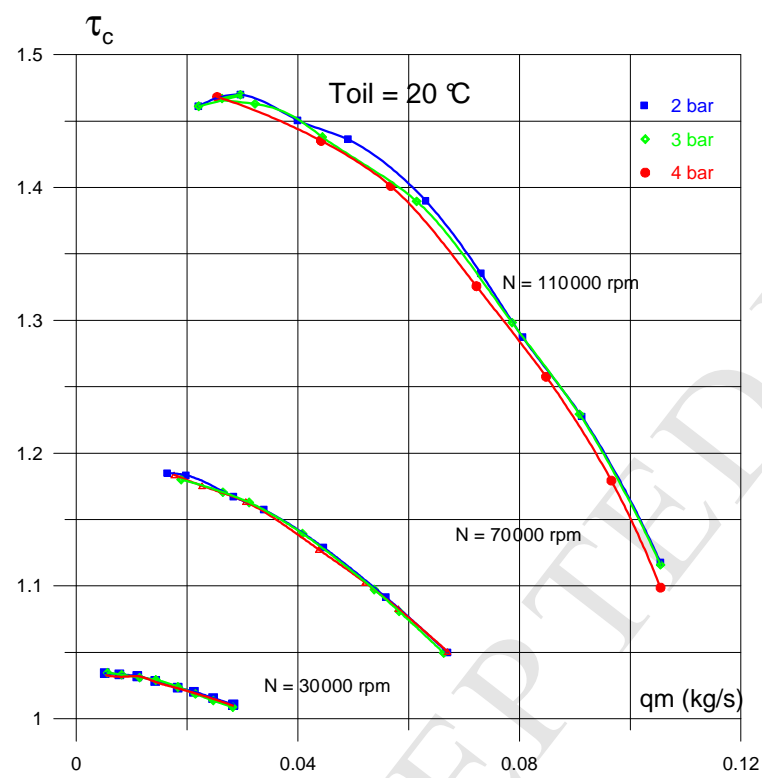

Fig. 9 - Compression ratio vs. air flow rate

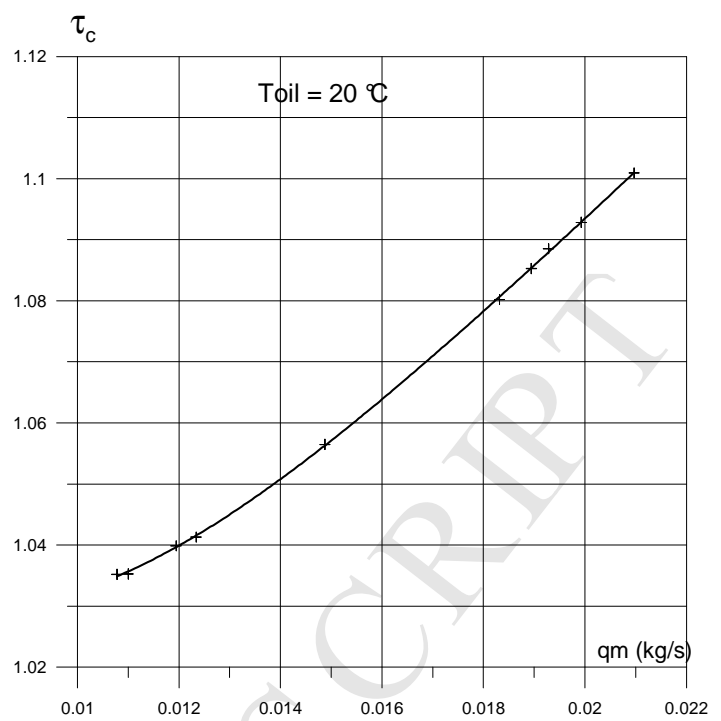

Fig. 8 - Compression ratio vs. air flow rate

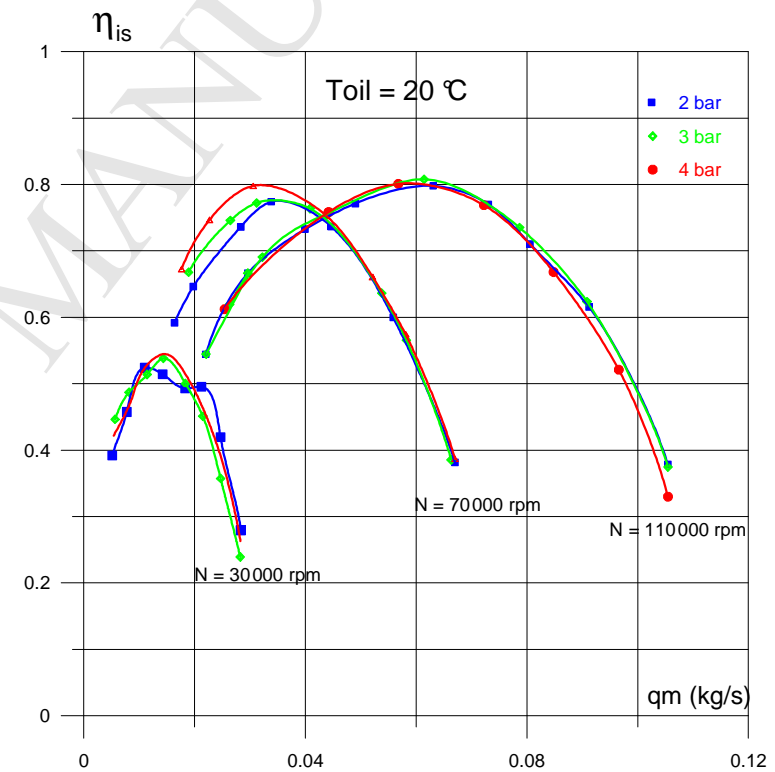

Fig. 10 - Isentropic efficiency vs. air flow rate 


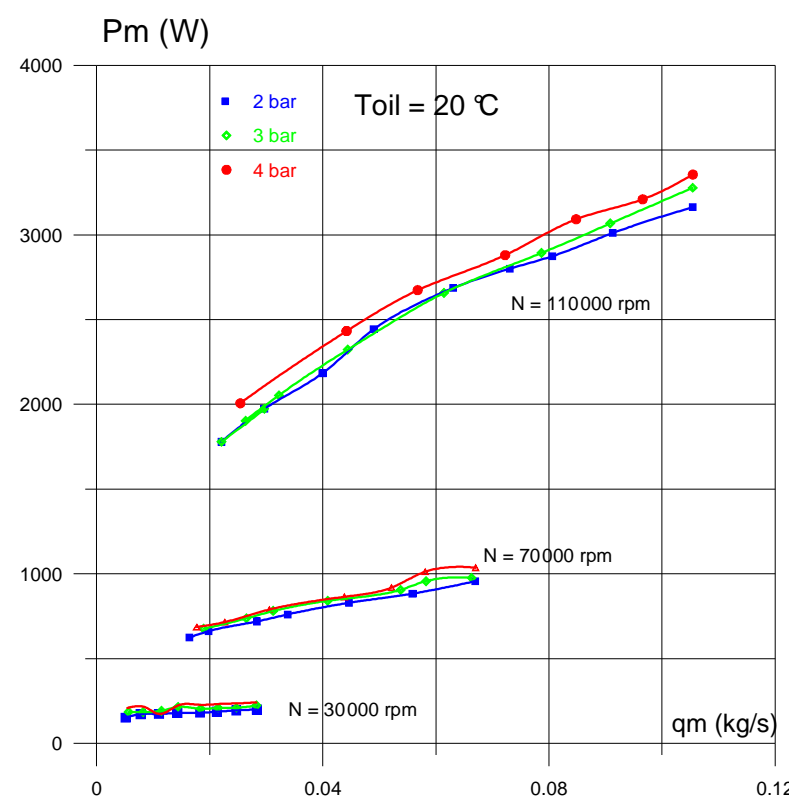

Fig. 11 - Mechanical power vs. air flow rate

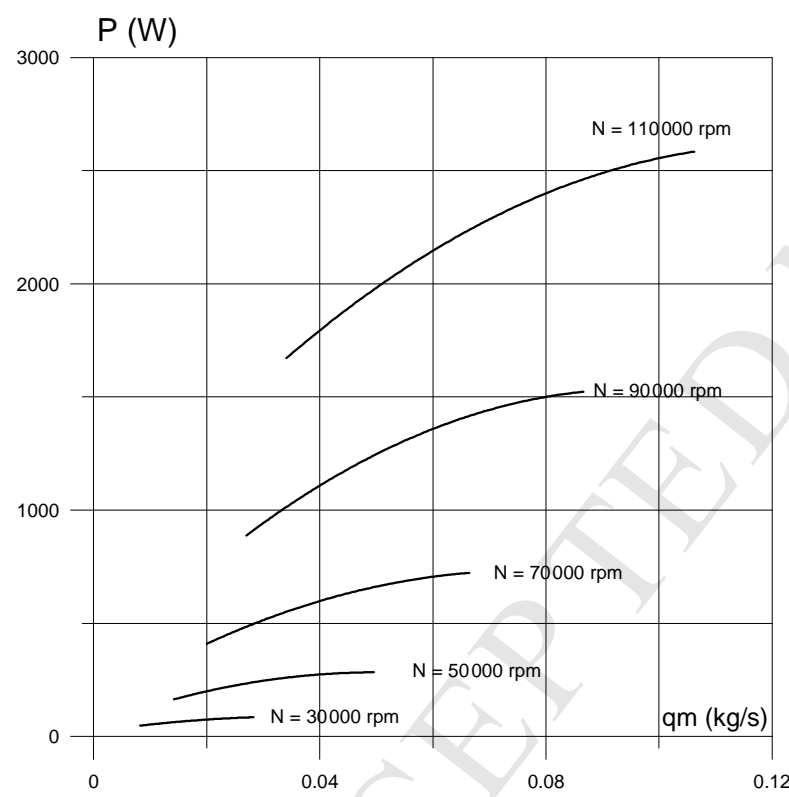

Fig. 13 - Compressor power vs. air flow rate

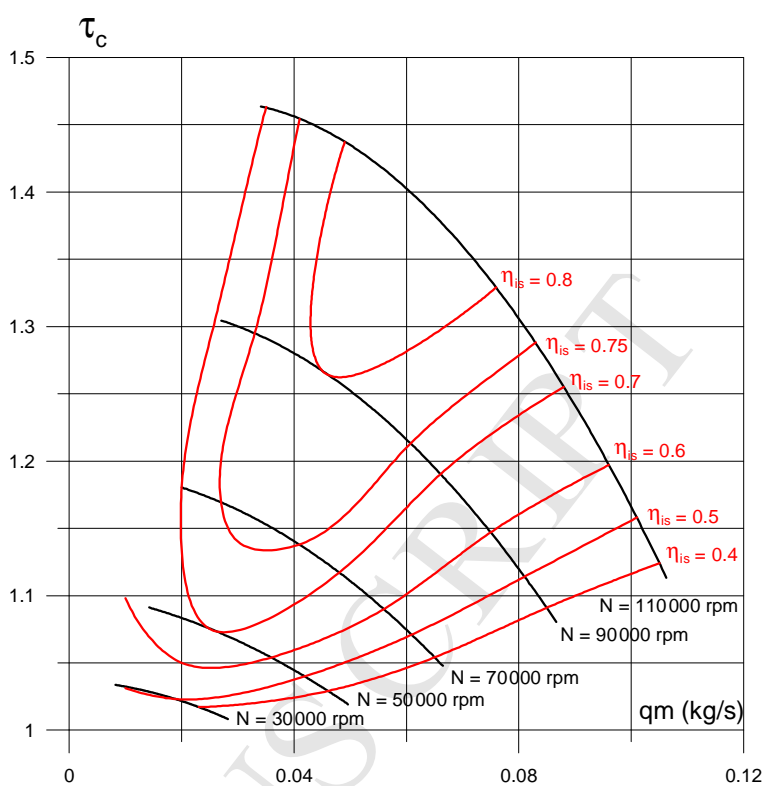

Fig. 12 - Compressor characteristic curves

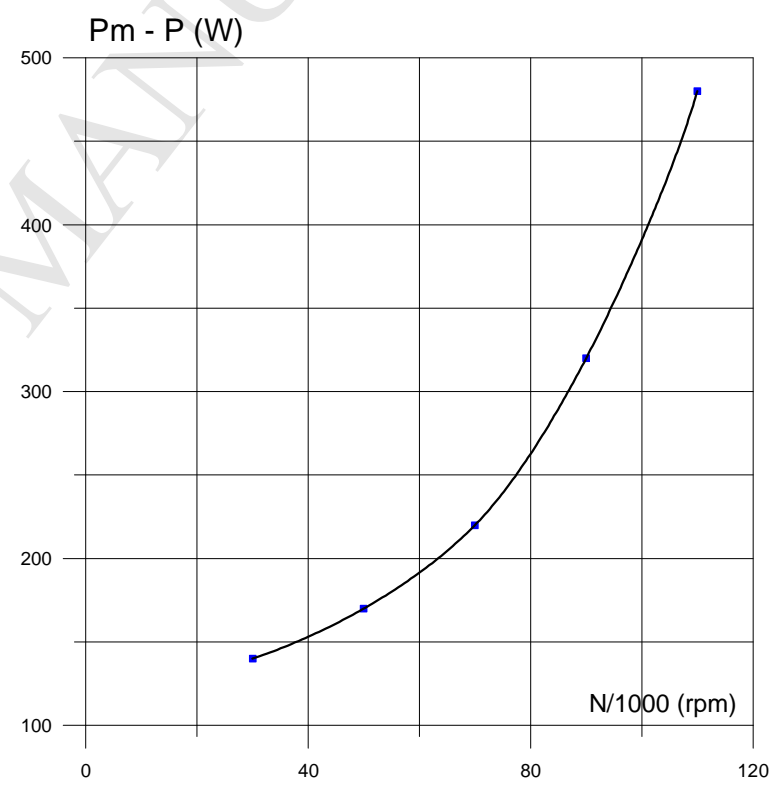

Fig. 14 - Mechanical power losses vs. rotational speed 


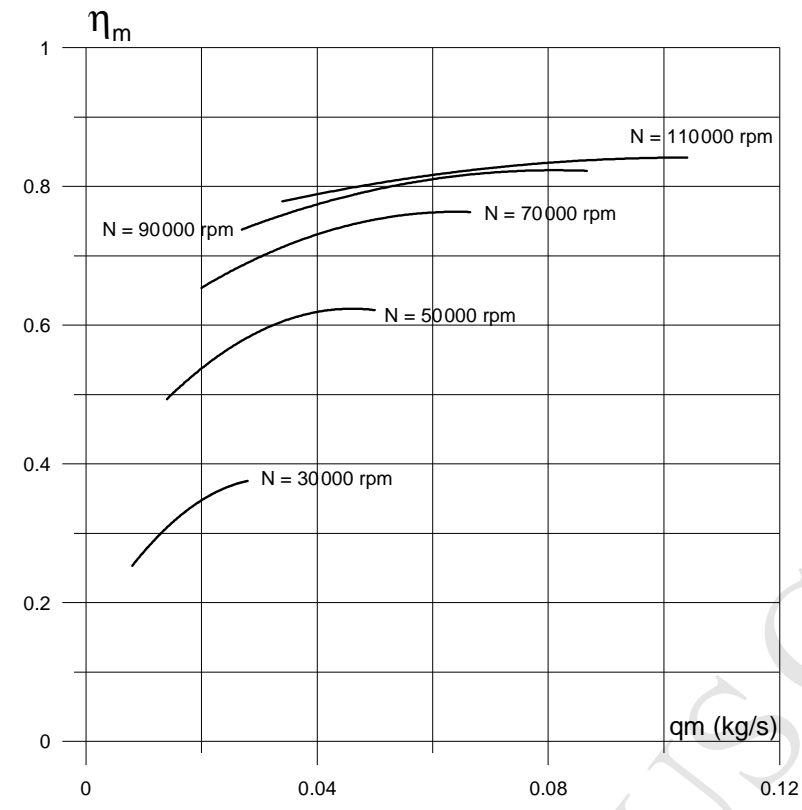

Fig. 15 - Mechanical efficiency vs. air flow rate 